\title{
Perfiles
}

ROODY RÉSERVE

\section{Edward W. Said: testimonio de una visión alternativa}

El día de su muerte, el pasado miércoles 24 de septiembre, puede decirse - parafraseando a Victor Hugo en su famosa declaración sobre la muerte de François Arago-, que simboliza una disminución de la luz. Lo que hizo brillar de manera especial a Edward Said durante sus 67 años de vida fue su visión alternativa sobre el drama palestino, o lo que equivale a lo mismo, su singular concepción de la relación entre Oriente y Occidente. Nada más echar un vistazo a su Orientalism, publicado en 1978, sugestivamente subtitulado en la traducción francesa "Oriente creado por el Occidente", para darse cuenta de esta marca distintiva. En este libro Said denuncia un discurso intelectual occidental que pretende enmascarar una voluntad de dominación del mundo oriental. Resumiendo, en palabras de Pedro Martínez Montávez, en su prólogo al libro Palestina: paz sin territorios, publicado por la editorial Txalaparta, se puede decir que "el profesor Said [tuvo] la elegancia de ser un inconformista, la intrepidez de un polemista y la ejemplaridad de ser un estudioso".

$\mathrm{Y}$, en uno de sus primeros estudios, analizó la "fascinación" que existe en Occidente por el mundo oriental. El orientalismo (conjunto 
de disciplinas, instituciones, procesos de investigación y estilos de pensamiento que modelaron el "conocimiento" de Occidente del mundo oriental), aprisiona a su "objeto de estudio", el árabe, el musulmán, en un círculo desde donde reafirma su poder sobre éste y remarca la pretendida superioridad de su mundo. "La red de racismo, estereotipos culturales, imperialismo político, ideología deshumanizadora que aprisiona al árabe y al musulmán —observa Said- es realmente muy fuerte. Es esta la red que todo palestino ha llegado a interiorizar como un insólito y lacerante destino (...) El nexo de conocimiento y poder que ha creado "al oriental” y que, en cierto sentido, lo desecha como ser humano no es, y menos aún para mí, una cuestión exclusivamente académica. Pero sí es una cuestión intelectual cuya importancia resulta obvia".

Nuestro autor abordó con realismo y espíritu crítico su identidad de intelectual proveniente de un pueblo víctima de la colonización. Por ello, entendió que su misión consistía en recordar no sólo el colonialismo, sino también destacar sus efectos presentes en la vida de los pueblos, especialmente del suyo. Porque el intelectual y su pueblo llevan su pasado (en este caso su presente) de colonizado "como cicatrices y heridas humillantes, como instigación a diferentes prácticas, como visiones del pasado potencialmente revisadas que tienden al futuro, como experiencias que apremia reinterpretar y redesplegar en las que el nativo antes silenciado se exprese y actúe en un ámbito recuperado de manos de los colonialistas".

En consecuencia, Said dedicó buena parte de su labor intelectual tratando de desenmascarar las tretas de un discurso anti árabe, racista y tributario, en buena medida, del colonialismo arrogante de Europa. El desplazamiento de ésta por los Estados Unidos no ha significado una revisión del discurso sobre Oriente y el fin de la dominación. Al contrario, se sigue viendo al árabe musulmán como esencialmente terrorista y radicalmente inferior al hombre occidental. De esta suerte, diría Said, todavía se cree, tal como afirmara Ernest Renan en 1896, que los países mahometanos son inferiores a los occidentales.

En opinión de Said, esta concepción sigue manifestándose gracias a famosos intelectuales occidentales que ven en el mundo musulmán el principal reto para el triunfo de los valores occidentales, luego del fin de la guerra fría. Decía el autor de Palestina, Paz sin territorios, en 1997, que estos intelectuales se esfuerzan "en dibujar el Islam en los medios de comunicación como una religión y una cultura dominadas 
por un vesánico odio hacia la modernidad en sí, y en particular hacia EEUU, cuya política exterior, según aseguraban tales profetas de la concordia y la ilustración, se caracterizaba por la neutralidad y el altruismo, apenas empañados por alguna ligereza menor. Como prueba de la extensión de esta corriente en los últimos tiempos, podemos recordar el famoso artículo de Samuel Huntington sobre "la lucha de culturas". (...) La tesis principal de Huntington era que Occidente, a fin de salir victorioso de los nuevos conflictos que sucederían a la Guerra Fría, debía enfrentarse al peligro islámico y estar prevenido frente a otra amenaza, en su opinión (que no sustenta con ningún argumento) más grave y preocupante: el establecimiento de una alianza entre el Islam y el confucianismo. El otro malévolo enemigo de los valores occidentales".

Frente a las "explicaciones racistas" que hacen del "otro" oriental un terrorista, antimoderno y antiestadounidense, Said ofrece una visión alternativa en perfecta sintonía con su papel de intelectual palestino, profundamente marcado por su exilio propio y el de sus seres queridos. Fundamenta su tarea en la firme convicción que el intelectual debe ser capaz de "esgrimir pautas de verdad acerca de las penalidades y de la opresión humanas, al margen de [sus] afiliaciones partidarias, origen nacional y lealtades primigenias. Nada deforma más la actividad del intelectual público como el deliberado y medido silencio, el exabrupto patriótico y la apostasía victimista". Para ello, sus actividades no deben ser predecibles, ni adscritas a algún dogma ortodoxo. Si bien el intelectual no tiene por qué evitar manifestar su solidaridad con determinada causa, ésta no puede anteponerse a la crítica. Sólo en esta medida, podrá elevarse sobre los intereses mezquinos y dar perfecta cuenta de la realidad de su pueblo, especialmente cuando se trata de un pueblo sufrido, víctima del colonialismo más atroz.

Gracias a estas aclaraciones de partida, Said se encontró cómodo para poder seguir denunciando la situación de los palestinos y, al mismo tiempo, mantener un pulso heroico en su enfrentamiento con los líderes de su pueblo que, según él, han traicionado la causa de éste. Así, denunció, desde un principio, en contra de las opiniones dominantes en este entonces, tanto el liderazgo palestino que negoció los Acuerdos de Oslo como la idea subyacente que animaron a los líderes israelíes que lo promovieron. Decía de Yaser Arafat que quedó en el rol de un jefe nativo de pacotilla, controlado por los colonos blancos.

809

Perfiles 
$\mathrm{Y}$, acerca de los Acuerdos, mientras que casi todo el mundo occidental veía en ellos el único camino de salida al sufrimiento de palestinos e israelíes, declaró Said poco tiempo después, "el actual proceso de paz debe ser considerado una prolongación de la política israelí de ocupación. Sólo puede llevar a la demora y el estorbo, y tal vez incluso la puntilla, de la más mínima oportunidad que haya existido a lo largo de dos décadas de alcanza una paz basada en la progresiva reconciliación entre la parte que ha sufrido la impostura, el pueblo palestino, cuyas tierras han sido expoliadas, que fue dispersado en 1967 (la más larga ocupación militar continuada del siglo XX), que ha sido privado de cualquier tipo de representación parlamentaria y de la posibilidad de elegir su destino; posibilidad de reconciliación entre esta parte, digo y entre la principal responsable de todas sus desgracias: Israel y sus mandos militares".

Said experimentó en carne propia, desde muy joven, las desgracias del pueblo palestino. Nació en Jerusalén, bajo mandato británico, el $1^{\circ}$ de noviembre de 1935 . Un año después, se declaró la Primera Intifada en contra de la política de Gran Bretaña de favorecer la instalación de colonos judios en Palestina. En 1947, su familia tuvo que dejar Jerusalén y todas sus pertenencias, debido a la violencia que se abatió desde entonces sobre la población palestina, en el contexto —en palabras de Henry Cattan- del "terrorismo judío, la expulsión y la crisis de la seguridad y de la maquinaria gubernamental para la conservación de la paz y el orden durante los últimos meses del mandato" británico. Así, Said pasó parte de su juventud en el Líbano y el Cairo. Y, su formación intelectual se desarrolló, especialmente, en los Estados Unidos donde trabajó como profesor de literatura inglesa y comparada en la Universidad de Columbia de Nueva York.

Said, -en Verdad y Reconciliación, publicado en el New York Times Magazine el 10 de enero de 1999-, recalca esta idea cuando rememora las razones por las que el pueblo palestino abandonó sus hogares y establece los primeros objetivos de los colonos judíos y las autoridades británicas que ampararon la colonización. "No - dice Said-, los palestinos no huyeron porque sus líderes les dijeron que lo hicieran, sino porque uno de los objetivos de la guerra era vaciar Palestina del mayor número posible de árabes; no, el Reino Unido no se opuso al sionismo, sino que lo alentó cuidadosamente; no, los ejércitos árabes no trataron de destruir Israel en 1948, dado que Jordania 
en particular, que quería y obtuvo Cisjordania, actuó en connivencia con Israel; y no, los árabes no se opusieron a la paz después de 1948, puesto que todos sus principales líderes pidieron tratados de paz oficiales, pero Ben Gurion los rechazó".

La madre de Said seguirá considerándose exiliada palestina hasta su muerte. Este último también terminaría su vida en el exilio, como ha sucedido con muchos de sus compatriotas que tuvieron que salirse de la Palestina de 1948, luego de la declaración de independencia de Israel, el 14 de mayo de ese año. En su análisis de la situación del exiliado, Said retrasó de manera conmovedora lo que se podría considerar como su propia lacerante historia. Por eso, dirán Ashcroft y Ahluwalia, "Said ve similitudes entre el exilio y la proscripción en tanto que situación que hace de la víctima un perpetuo proscrito. El exilio no implica una total separación del lugar de origen, es más bien una situación en la que el exiliado nunca llega a abandonar lo antiguo ni acepta completamente lo nuevo. No se trata de un estado que pueda llegar a satisfacer, en el que el exiliado pueda sentirse cómodo y seguro. Es más bien un estado que aguza la propia capacidad de supervivencia".

Entonces, cabe preguntarse: ¿por qué un personaje tan importante, que ha tenido tanta lucidez en la descripción de la situación de su pueblo, que ha desmembrado con argumentos irrefutables la hipocresía, la arrogancia y la injusticia del mundo para con su pueblo; por qué Said nunca apoyó los esfuerzos de los actuales dirigentes palestinos de hacer la paz con Israel? ¿Será que este intelectual simpático que solía presentarse como un personaje independiente fuera, al fin -como suelen pensar muchos occidentales-, un árabe terrorista, partidario del aniquilamiento de Israel por la vía de las armas y de los atentados suicidas? ¿O, será que, tal como lo sostuvo Yasir Arafat, que son posturas típicas de intelectuales que viven cómodamente en el exilio y que no tienen mucho interés en la miseria de los que se quedaron, no obstante que ganan prestigios y dinero hablando de la situación en Palestina?

Para empezar contestando a la pregunta de por qué el rechazo de Said a los Acuerdos de Oslo y sus sucedáneos pequeños acuerdos, cabe aclarar, en primer lugar un hecho relevante: "Quiero ser claro en este punto: —dice Said- nunca he apoyado, ni puesto mis esperanzas en una solución militar al conflicto palestino-israelí. [Es más], estoy convencido de que es imposible recuperar lo que perdimos como 
pueblo en 1948, a pesar de todos los compromisos internacionales existentes acerca de los derechos de los refugiados, a pesar de las resoluciones de la ONU que afirman, un año tras otro, que los refugiados de 1948 tienen derecho a retornar a sus casas o conseguir indemnizaciones. Siempre he pensado que el único camino que hay entre nosotros es llegar a una solución intermedia histórica, a condición de que esta solución preserve la unidad de nuestro pueblo y haga honor - sin ambigüedad-a nuestra historia, al significado latente de nuestra lucha".

Pero, ¿̇los Acuerdos de Oslo, negociados bajo la mirada atenta de la Comunidad Internacional, no constituyen esta solución intermedia de la que dice Said ser partidario?. No, dijo nuestro autor. Este acuerdo, al contrario, ha significado muchos retrocesos para el pueblo palestino. "El proceso de paz - dice el autor de The Politics of Dispossession - promovido por Estados Unidos, se edificó cruelmente sobre el sufrimiento de un pueblo cuya sociedad había sido destruida en 1948 por la llegada de una población israelí que afirmaba tener derechos bíblicos sobre Palestina. Dos terceras partes de los habitantes de aquel territorio fueron expulsados de sus hogares. En 1967, Israel ocupó el resto de la Palestina histórica. Sin embargo, Oslo ni puso fin a la desposesión palestina, ni alivió verdaderamente a corto plazo las miserias de una ocupación militar israelí durante la cual la economía, la infraestructura y los recursos humanos de los palestinos han sido sistemáticamente destruidos”.

Hay muchos culpables y muchas razones que explican esta visión absolutamente parcial de los términos en que se debería de edificar la paz entre los palestinos e Israel. "En primer lugar, parte de la culpa recae sobre la actual dirección de la OLP, que desde un principio alabó "el coraje" de Israel al otorgar a los palestinos el derecho a un autogobierno extremadamente limitado (aunque, ahora, incluso éste parece lejos de materializarse). Por qué las víctimas de la destructiva política israelí de despojo, ocupación militar y represión deben agradecer a sus perseguidores que admitan de mal grado que ellos existen, es difícil de entender; no obstante, las memorias recientemente publicadas de Mahmud Abbas, (Abu Mazen) proporcionan, al menos una clave importante. La necesidad psicológica de ser reconocidos por el "movimiento sionista" era tan importante para gente como él y Arafat como para soslayar casi toda consideración, especialmente aquellas 
concernientes a los intereses reales y a largo plazo de los palestinos. Esto es índice de cuán inseguros en su propia causa, sus logros y su historia, se encontraban los negociadores palestinos en Oslo; y de cómo confundieron la satisfacción de sus propias necesidades personales con una victoria política real".

Este deseo de protagonismo de Arafat, su gusto por el poder autoritario, en opinión de Said, es uno de los principales valladares en la defensa correcta de la causa palestina. Además, este personaje se empeñaría en dinamitar cualquier posibilidad de unión del pueblo palestino en contra de la autocracia, la corrupción o el simple cinismo del mundo occidental. En una declaración sobre el estado de corrupción favorecida desde la máxima dirigencia de la autoridad palestina, dice Said, "Arafat no sólo no tiene idea de lo que es una auténtica responsabilidad de gobierno, sino que cree que puede engañar a todo el mundo con sus evasivas y sus bravatas. No hace falta recordar a nadie que en los Territorios la palabra de Arafat es ley; él es la autoridad, y sin él se puede hacer muy poco; él es la única fuente de mecenazgo, sólo él conoce plenamente el alcance de los presupuestos".

También los Estados Unidos tendrían cierta responsabilidad en el mantenimiento de la situación desastrosa de vida de los palestinos. La política internacional de este país ha sido la principal fuente de apoyo para Israel desde hace más de cincuenta años. Además, en algunos sectores muy influyentes de este país, dice Said, existe una especie de entusiasmo ingenuo y atávico que consiste en celebrar todo lo que haga el gobierno israelí, no obstante sus flagrantes violaciones a los derechos humanos más elementales de los palestinos. En un texto publicado en The Guardian, el 2 de mayo de 1998, intitulado, Cincuenta años de desposesión, nuestro autor, en el contexto de la celebración de medio siglo de la independencia de Israel, analizó el discurso ideológico y sesgado que se suele propagar en los Estados Unidos sobre este país. Allí, se proyectó a Israel como "un estado pionero, lleno de esperanzas y promesas de para los supervivientes del Holocausto nazi, un refugio de liberalismo en un mar de fanatismo y reacción árabes". Sin embargo, según Said, ahogaron "el hecho de que ha transcurrido medio siglo sin la restitución ni el reconocimiento por parte israelí de los derechos de los palestinos, $\mathrm{y}$, - tal como los hechos muestran sin ninguna duda- sin vincular dicha suspensión de derechos a las políticas oficiales de Israel".

813 
Finalmente, para Said, en la misma concepción del Estado de Israel, habría que encontrar el origen de la desgracia que se ha abatido sobre los palestinos. "Israel - dice Said- fue el resultado de numerosos factores, principalmente del deseo imperialista de dividir y gobernar, aliado con un programa sionista decidido también a acabar con la opresión antisemita". En esta medida, equipara la desposesión de los suyos con la edificación de la nación israelí. Por eso, propone que aceptemos "la experiencia judía con todo lo que supone de horror y espanto; pero también debemos exigir (hablando de los palestinos) que no se preste menos atención a nuestra experiencia, aunque quizás en otro plano de la realidad histórica". Said aclara, enseguida, que no se trata de equiparar el genocidio del Holocausto con la desposesión masiva de la que fue víctima su pueblo. Se trata más bien de reconocer la conexión que existe entre ambos hechos.

Las principales tesis de Said sobre el colonialismo, el conflicto palestino israelí; en fin, toda su obra ha sido objeto de intensos debates. Ni sus propios compatriotas aceptaron alegremente sus opiniones sobre el proceso de paz y sus críticas en contra de Yasir Arafat. Éste dijo, más o menos de él que era un oportunista que recién se estaba subiendo al carro del patriotismo. Por otro lado, durante más de veinte años Said mantuvo un agrio duelo con Bernard Lewis, el orientalista más célebre de nuestros días. Está de más recordar aquí que Lewis refuta todos los argumentos de Said sobre los problemas actuales en Oriente y la relación de esta parte del mundo con Occidente. Sin embargo, al periodista que le abordó sobre, luego de la muerte de Said, contestó: "De mortuis nibil nisi bonum.

\section{Bibliografía}

Ahluwalia, Pal y Ashcroft, Bill, Edward Said: la paradoja de la identidad, Edicions Bellaterra, Barcelona, 2000.

Catta, Henry, Palestina, Los árabes e Israel, Siglo XXI Editores, México, 1971.

Said, Edward, Palestina: paz sin territorios, Editorial Txalaparta S.L. 1997.

- Crónicas Palestinas: árabes e israelies ante el nuevo milenio, Grijalbo Mondadori, S. A., Barcelona, 2001.

-Orientalism, New York, Vintage Books, 1979 